\title{
La producción científica en educación inclusiva: avances y desafios
}

Scientific Production in Inclusive Education: Progress and Challenges

A produção científica na educação inclusiva: avanços e desafios

Ana Iglesias Rodríguez* iD https://orcid.org/0000-0002-6921-8513

Yolanda Martín González** (iD https://orcid.org/0000-0002-6353-7644

Doi: 10.17227/rce.num78-9885

Para citar este artículo: Iglesias, A. y Martín, Y. (2020). La producción científica en educación inclusiva: avances y desafíos. Revista Colombiana de Educación, 78, 383-418. http://doi.org/10.17227/rce.num78-9885

\section{(c) $(1) \Theta$}

* $\quad$ Doctora en Pedagogía de la Universidad de Salamanca, España. Profesora Titular en el área de Didáctica y Organización Escolar de la Universidad de Salamanca, Ávila, España. Correo electrónico: anaiglesias@a usal.es

** Doctora en Documentación de la Universidad de Salamanca, España. Profesora Titular en el área de Bi blioteconomía y Documentación de la Universidad de Salamanca, Salamanca, España. Correo electrónico: ymargon@usal.es 


\section{Resumen}

El propósito de este artículo de revisión es conocer la evolución de la educación inclusiva como objeto de investigación, tomando como referencia la producción científica generada durante los 25 años transcurridos desde la Declaración de Salamanca, para valorar qué retos quedan por cumplir y orientar todas las acciones y esfuerzos en esta dirección. Para ello, se ha realizado un análisis bibliométrico, basado en los parámetros de autoría, revista y artículo científico, de aquellos estudios en lengua española centrados en la educación inclusiva desde el año 1994 hasta la actualidad, publicados en revistas indexadas de la base de datos Scopus. Los resultados muestran que son escasos los estudios hechos en español sobre esta materia; que los autores desarrollan su labor principalmente en el ámbito universitario y de manera individual o en grupos de dos o tres; que el acceso y visibilidad de los trabajos se encuentra aún limitado al ser escasas las publicaciones editadas en acceso abierto y al no ocupar las revistas posiciones relevantes en el Scimago Journal Rank (sJR); y, por último, que la publicación de los artículos se concentra en los últimos 10 años siendo el número de citas recibidas una o ninguna. Esto indica la escasa relevancia de los trabajos en estudios científicos posteriores. En suma, las acciones, tanto en el ámbito nacional como internacional, han generado importantes logros, pero sigue siendo preciso abordar los numerosos desafios que quedan pendientes, no exentos de obstáculos pero sí repletos de nuevos estímulos orientados a la acción, a la reflexión y al compromiso docente.

\section{Palabras clave}

educación; educación igualitaria; formación del profesorado; investigación científica; revistas

\section{Keywords}

education; equal education; tutor training; scientific research; periodicals

\begin{abstract}
This review article aims to trace the development of inclusive education as a research object taking as a reference the scientific production generated since the Salamanca Declaration with a view to assess both the achievements and the challenges ahead so that we may prioritize our actions and define our future agenda accordingly. In order to do so, a bibliometric analysis, based on the parameters of authorship, journal and scientific article, has been carried out of those Spanish-language studies focusing on inclusive education from the year 1994 up until now, published in Scopus database indexed journals. The results drawn from our analysis evince five main findings, namely, that these studies are still scarce; that their authors pursue their research under the university institutional umbrella; that they mostly work either individually or in small teams of not more than three members; that the availability and visibility of their outcomes are very limited because there are still few open-access publications and they are published in journals which are not prominent in the Scimago Journal Rank (SJR); and, finally, that they have largely seen the light in the last ten years and have been cited only once or not at all, which reveals that their relevance for subsequent scientific studies is meagre. As a way of conclusion, we can attest to the import of the initiatives taken in this area of research, even if it is still much necessary to keep on facing numerous challenges which, albeit not exempt from obstacles, are at the same time filled with opportunities and constitute unprecedented stimuli for action, reflection, and educational engagement.
\end{abstract}

\section{Resumo}

O objetivo deste artigo de revisão é conhecer a evolução da educação inclusiva como objeto de pesquisa, tomando como referência a produção científica gerada durante os 25 anos transcorridos desde a Declaração de Salamanca, para avaliar quais desafios ainda não foram cumpridos e orientar todas as ações e esforços nesta direção. Para tal, foi realizada uma análise bibliométrica, baseada nos parâmetros de autoria, revista e artigo científico, de estudos en língua espanhola sobre a educação inclusiva desde o ano de 1994 até o momento atual, publicados em revistas indexadas na base de dados Scopus. Os resultados mostram que são escassos os estudos realizados em espanhol sobre este tema; que os autores desenvolvem seu trabalho principalmente no âmbito universitário e de maneira individual ou em grupos de dois ou três; que o acesso e a visibilidade dos trabalhos são ainda limitados por serem poucas as publicações editadas en acesso aberto e porque as revistas não estão em posições relevantes no Scimago Journal Rank (SIR); e, por último, que a publicação de artigos se concentra nos últimos 10 anos sendo o número de citações recebidas uma ou nenhuma. Este quadro indica a pouca relevância dos trabalhos nos estudos científicos posteriores. Em suma, as açōes, tanto no âmbito nacional como internacional, geraram importantes conquistas, mas ainda é preciso abordar os numerosos desafios pendentes, não isentos de obstáculos, mas repeltos de novos estímulos orientados à ação, à reflexão e o comprometimento docente.

\section{Palavras-chave}

educação; educação igualitária; formação docente; pesquisa científica; revistas 


\section{Introducción}

El año 2019 cobra una especial relevancia en lo que se refiere a dos cuestiones fundamentales -que en realidad son solo una- que deberían formar parte de una sociedad y de un mundo plural y diverso como el nuestro: la inclusión y la educación para todos.

Decimos que dicho periodo es relevante porque a lo largo de este celebramos, por un lado, 30 años de la Convención de los derechos del niño (Unicef, 2006) que fue aprobada como tratado internacional de derechos humanos el 20 de noviembre de 1989; y, por otro lado, 25 años desde que la Conferencia Mundial sobre Necesidades Educativas Especiales: Acceso y Calidad, aprobara la Declaración de Salamanca y marco de acción para las necesidades educativas especiales, hecho que se gestó el 10 de junio de 1994.

La Declaración de Salamanca (Unesco, 1994) supuso un punto de inflexión fundamental para lograr un cambio de paradigma en la concepción de la educación especial (Martínez, De Haro y Escarbajal, 2010; García Rubio, 2017). En ella se habla de escuelas integradoras para incluir a los niños -no debemos olvidar que nos encontramos en el año 1994-, poniendo el acento en aquellos que durante tanto tiempo habían estado separados y segregados del sistema educativo. El mensaje que se desprendía y fluía en quienes tuvieron la oportunidad de participar en este gran acontecimiento (Echeita y Verdugo, 2004) era que la escuela debía prepararse para acoger, para dar la bienvenida a todas estas personas y, en consecuencia, para proporcionarles una educación de calidad y de equidad (Arias, 2014; Muñoz, López y Assaél, 2015; Valdunquillo e Iglesias, 2015; Navarro-Montaño, 2017; Boroel, Sánchez, Morales y Henríquez, 2018). Toda vez que esta Declaración tiene en cuenta y toma como referencia la Declaración Universal de los Derechos Humanos de 1948 (ONU, 2015), proclamada y aprobada por la Asamblea General de las Naciones Unidas, en la que se habla ya de educación para todos y en la que se expresaron por primera vez,

[...] los derechos y las libertades a los que todo ser humano puede aspirar de manera inalienable y en condiciones de igualdad. [...] La Declaración constituye los fundamentos de un futuro justo y digno para todos y brinda a las personas de todo el mundo un poderoso instrumento en la lucha contra la opresión, la impunidad y las afrentas a la dignidad humana. [...] "todos los seres humanos nacen libres e iguales en dignidad y derechos". (pp. iii-v)

De igual forma, asume lo establecido en la Declaración mundial sobre educación para todos y el marco de acción para satisfacer las necesidades básicas de aprendizaje (Unesco, 1990), aprobados por la Conferencia Mundial sobre Educación para Todos en Jomtien (Tailandia) en marzo de 1990, donde se puso el acento en que el objetivo prioritario era (y es) la 
educación para todos a lo largo de toda la vida; en concreto, en "satisfacer las necesidades básicas de aprendizaje de todos los niños, jóvenes y adultos" (artículo 3. Universalizar el acceso a la educación y fomentar la equidad). También, lo señalado más adelante, en marzo de 1994, en las denominadas "Normas Uniformes sobre la igualdad de oportunidades para las personas con discapacidad" (Resolución aprobada por la Asamblea General de Naciones Unidas [sobre la base del informe de la Tercera Comisión (A/48/627)]), en su artículo 6 que versa sobre educación y en el que se insta a:

[...] los Estados a reconocer el principio de la igualdad de oportunidades de educación en los niveles primario, secundario y superior para los niños, los jóvenes y los adultos con discapacidad en entornos integrados, y deben velar por que la educación de las personas con discapacidad constituya una parte integrante del sistema de enseñanza. (ONU, 1994, p. 16)

A todo ello habría que añadir, hoy más que nunca, por su relevancia actual, lo instituido en la Carta de los Derechos Fundamentales de la Unión Europea (Diario Oficial de las Comunidades Europeas, 2000), proclamada por el Parlamento Europeo, el Consejo y la Comisión en el año 2000, donde en su preámbulo afirma:

Consciente de su patrimonio espiritual y moral, la Unión está fundada sobre los valores indivisibles y universales de la dignidad humana, la libertad, la igualdad y la solidaridad, y se basa en los principios de la democracia y del Estado de Derecho. Al instituir la ciudadanía de la Unión y crear un espacio de libertad, seguridad y justicia, sitúa a la persona en el centro de su actuación. (p. C 364/8)

Como se puede observar, la educación, en el sentido más amplio de su significado, ha sido y sigue siendo una de las principales preocupaciones de todos los gobiernos y de los diferentes organismos internacionales (Azorín, 2017a), quedando patente en lo

[...] proclamado y acordado por las Naciones Unidas en la Declaración Universal de Derechos Humanos y en los pactos internacionales de derechos humanos, que toda persona tiene todos los derechos y libertades enunciados en ellos, sin distinción alguna, por motivos de raza, color, sexo, idioma, religión, opinión política o de otra índole, origen nacional o social, posición económica, nacimiento o cualquier otra condición. (Unicef, 2006, p. 8)

Y también en la Convención de Naciones Unidas sobre Derechos de las Personas con Discapacidad, ratificada por España en 2008, cuando en su artículo 24 versa: "[...] los Estados Partes asegurarán un sistema de educación inclusivo a todos los niveles, así como la enseñanza a lo largo de 
la vida [...]". Además, en su artículo 7.3, como ya se hiciera anteriormente en la Convención de los Derechos del Niño en 1989, en el artículo 12, se hace referencia probablemente a uno de los derechos más importantes otorgados a una persona, en este caso, a los niños y niñas -derecho que no tienen los adultos- que es el siguiente: "Los Estados Partes garantizarán que los niños y niñas tengan derecho a expresar su opinión libremente sobre todos los asuntos que les afecten, opinión que recibirá la debida consideración teniendo en cuenta su edad y madurez". Derecho, dicho sea de paso, que los niños y niñas deberían ejercer pero no lo hacen y los adultos no cumplen.

En suma, se podría decir que la Declaración de Salamanca junto a otras declaraciones ya mencionadas, supusieron el compromiso de todos los gobiernos y de sus políticas educativas de poner en práctica políticas de inclusión; hecho que se convirtió en un paso importante para todos los sistemas educativos que, sin duda, han de estar preparados para aceptar y atender en las mejores condiciones y con la mayor calidad posible a todos los niños y niñas. A este respecto hay que destacar que llevar a cabo la filosofía inclusiva que subyacía a estas Declaraciones, no hubiera sido posible sin el trabajo constante y desinteresado de diferentes profesionales entre los que cabe destacar Tony Booth, Mel Ainscow, William Stainback o Robert Schalock, entre otros, procedentes de ámbitos diversos (educación, sociología, antropología, psicología, etc.), capaces de conformar un cuerpo teórico acerca de la inclusión y del importante papel que cumple en todo este proceso el profesorado. Hacemos nuestras las palabras ofrecidas por el Secretario de Estado de Educación, Alejandro Tiana Ferrer, en la Mesa Redonda "25 años después de la Declaración de Salamanca", celebrada en Salamanca (España) el 8 de abril de 2019, dentro del XVI Congreso Internacional y XXXVI Jornadas de Universidad y Educación Inclusiva, cuando asegura: "Se necesita un profesorado implicado en esta tarea, no que se vea arrastrado a ella, sino que desarrolle todos los modos de ejercicio profesional, práctica profesional que necesita ese procedimiento, ese objetivo último de inclusión. Sin él, no será posible".

\section{Elementos esenciales en una educación para todos}

A lo largo de estos últimos 25 años, la inclusión, como paradigma de referencia que sustenta las políticas educativas de los diferentes países, está generando un replanteamiento sustancial en los programas de formación del profesorado (Colmenero, Pantoja y Pegalajar, 2015; Maestre, Nail y Rodríguez-Hidalgo, 2017; Aiello y Sharma, 2018; Carrillo et al., 2018; Moriña y Carballo, 2018; Mirón et al., 2019). Aunque sea necesario seguir haciéndolo, 
en el momento actual es preciso pasar de la reflexión a la acción; y, para ello, se requiere profesorado bien formado capaz de llevar a cabo una educación centrada en la persona, consciente de que cada ser humano es único y que como tal posee unas cualidades y unas necesidades que demandan, en palabras de Federico Mayor Zaragoza (2019), "el acompañamiento de un profesorado que sea capaz de realizar esta función, que seguramente es una de las funciones más bellas que existen, que es la de modular a todos los seres humanos para que puedan ser educados".

En la práctica, ese cambio, como sostiene Ken Robinson (2015) en su libro Escuelas creativas: la revolución que está transformando la educación, implica tres formas de discernimiento: (i) una crítica de la situación actual; (ii) una visión alternativa al actual estado de cosas allí donde se requieren mejoras; y (iii) una teoría transformadora para pasar de una a otra. Y, además, se necesita que "todos los docentes estén dotados de conocimientos suficientes sobre pedagogía y didácticas especiales, de aptitudes para actuar de manera inclusiva y de los valores y actitudes adecuados en relación con la educación inclusiva" (Aiello y Sharma, 2018, p. 209).

Por tanto, para lograr este cometido es menester que el profesorado, que es el encargado de aplicar las políticas de inclusión en las aulas y en los centros, estén formados de manera adecuada para abordar la diversidad de personas allí presentes (Sharma, 2011; González y Blanco, 2015; García-Barrera, 2017; Hernández e Iglesias, 2017). Algunas investigaciones (Shulman, 2005; Rouse, 2010; Sharma, 2011; Singleton, 2015) aluden a que son tres los aspectos que se deben cambiar para que un maestro sea inclusivo: el corazón (heart), las manos (hand) y la cabeza (head). A estas, nosotros añadiríamos que para lograr el equilibrio, antes de cambiar el corazón, las manos y la cabeza es fundamental cumplir con tres requisitos indispensables en la vida de un ser humano: ser educado, ser buena persona y ser íntegro (Iglesias, 2014, 2018).

Educar no se reduce a enseñar procedimientos y técnicas y tampoco consiste en formar técnicos. Educar consiste en promover el desarrollo integral de cada persona en todas sus dimensiones (cognitiva o intelectual, comunicativo-lingüística, afectiva, sensorio-motriz y de relación social), mediante el fomento de una buena disposición hacia el trabajo, capacidades diferentes, y a través del impulso de talentos, en procura de que la persona desarrolle todas estas cualidades consciente y libremente. Nunca se termina de aprender, por ello cada quien merece todo nuestro esfuerzo para ayudarlo a mejorar, respetando su personalidad.

Aun teniendo claras todas estas cuestiones, es tal la velocidad a la que se producen los cambios y de tal magnitud que a veces se olvida lo más esencial: aprender a ser persona. Y esto significa, entre otras cuestiones, formar sujetos buenos, educados e íntegros. 
Ser buena persona no es fácil. Implica esfuerzo, tesón, fuerza de voluntad, interés por aprender, equivocarse y saber reconocer los errores cometidos, abrir el corazón, creer en los demás, enriquecerse de y con lo que aportan los otros. Con toda seguridad, lo que define a cada uno como persona son los actos que realice en la vida. Y esas formas de actuar serán las que marcarán el rumbo de los acontecimientos presentes y futuros de su existencia. Como docentes, hemos de ser capaces de lograr que el alumno confíe en lo que le dicte la razón, pero también el corazón, para desarrollar en ellos la capacidad de ponerlo todo en acción. No debemos olvidar que cognición, corazón y acción son procesos que, acompasados, marcarán la diferencia en su vida. Por tanto, solo podremos Ilevar a cabo una enseñanza afectiva y efectiva de los valores y conductas sociales deseables, si forman parte íntegra de nuestra propia experiencia. Ejemplo de ello lo encontramos en ilustres pedagogos como Paulo Freire, John Dewey, María Montessori o Rosa Sensat, entre otros, que desde distintos pronunciamientos éticos, encarnan esta cualidad, y actualmente siguen siendo ejemplares por su testimonio personal y por las experiencias educativas que adelantaron.

Asimismo, tener educación significa creer firmemente en lo que se hace, a pesar de las dificultades a las que se enfrente en cada momento. La educación, nuestra educación y la educación de nuestros estudiantes viene precedida, en gran medida, por cómo somos concebidos y percibidos por los demás. Las personas no somos cosas sustituibles, como los objetos, ni meros instrumentos. Cada quien es único e irrepetible, y es dueño de sí mismo y de sus actos. De ello depende su dignidad que viene precedida, a su vez, por las relaciones que establece con los demás. En un contexto de cambios sociales y educativos profundos, como los que estamos viviendo en estos momentos, hoy, más que nunca, hemos de reflexionar y hacer reflexionar a nuestros estudiantes sobre la necesidad de aprender de todos y con todos. En este sentido, nuestros esfuerzos han de ir dirigidos a construir no solo conocimiento, sino sobre todo, buenos estilos afectivos y buenos hábitos de comportamiento, mediante un adecuado proceso de ayuda orientado a la adquisición de capacidades. Prueba de ello son las aportaciones de personas y profesionales que han incorporado en su agenda educativa otros aprendizajes que no se limitan a los saberes instrumentales, y apuntan a la necesidad de reconocer otras y múltiples inteligencias, como Howard Gardner; o el cultivo de sensibilidades emocionales, sociales y ecológicas, como Daniel Goleman, Vandana Shiva, etc.

Este compromiso afecta a todos: profesionales, estudiantes, familias, voluntarios, comunidad, pues a partir de un trabajo compartido debemos favorecer y propiciar un intercambio de vivencias variadas y estimulantes que generen un microcosmos de vida y de conciencia humana propio del que sabe acompañar, guiar y orientar en el difícil camino de la formación autónoma y del conocimiento de sí mismo (Iglesias y Beltrán, 2012). Este 
compromiso también exige que sometamos los saberes y las experiencias de conocimiento, a nuevos aprendizajes en contextos cambiantes y diferentes que requieran un diálogo social integrador y adecuado, para que todas las personas lleguen a comprender distintas realidades, experiencias y puntos de vista.

Ayudar a los estudiantes a expresar emociones, sentimientos, inquietudes, a resolver conflictos, compartir, colaborar y ser capaces de empatizar con los demás, entre otros aspectos, nos permite colocarles en el camino de la vida con un pequeño mapa en el que solo aparecen trazadas pequeñas líneas orientativas, que solo pretenden animarles a iniciar un viaje repleto de aventuras en el que deberán desarrollar al máximo la capacidad de participar directamente en una comunidad plural, en el que deberán emplear el diálogo como forma de comunicación, relación y resolución de conflictos, en el que habrán de tomar decisiones en cada situación y circunstancia, y en el que tendrán que esforzarse al máximo para tratar de entender las diferentes interpretaciones de la vida.

Por último, formar personas íntegras se convierte, en sí misma, en una gran tarea; porque no se nace acabado, se construye como persona a la par que construye su sociedad con otros. Esa integridad constituye una suerte de presencia revestida de presencia que no solo es un porte, una imagen, sino que es, ante todo, dignidad, humanidad, respeto, belleza, arte y valor; una especie de elegancia para afrontar los retos, para revelarse ante las injusticias, para luchar por nuestros derechos, para saber elegir. Y saber elegir forma parte de una filosofía de vida, de comportamientos, de actitudes y de aptitudes, de modos de ser, actuar y hacer. Ser elegante y saber elegir forman parte de un continuum que incita a quien posee esa cualidad a no hacer nada igual que los demás, aun pareciendo que todo se haga de la misma manera que el resto.

La elegancia imprime personalidad y esta se traduce en integridad. La integridad solo se adquiere si contamos con personas de referencia y entornos sociales que nos atraigan, seduzcan y provoquen a ser diferente mediante el saber y el conocimiento. Para los alumnos, los docentes somos esos referentes, un espejo en el que reflejarse; por eso, como docentes tenemos que conseguir que nuestros estudiantes no solo hagan las cosas bien, sino que hagan algo que deje huella en la sociedad, que dé respuestas a sus desafíos, a sus provocaciones, que ofrezca nuevas posibilidades, que favorezca su progreso, su desarrollo y el nuestro, y que genere condiciones adecuadas de vida y de bienestar.

Ser una persona íntegra constituye e instituye nuestra libertad, que es la condición básica para vivir y caminar. Pero la libertad no es individual. La verdadera libertad invita a quien la demanda a convertirse en miembro activo de pleno derecho y partícipe en una comunidad y a transformarse 
en individuos singulares y concretos dotados de cierto aire de naturalidad, espontaneidad y autenticidad, que permita que lo que los demás vean de nosotros responda a nuestro ser verdadero. Actuar espontáneamente, con gusto, belleza y estilo personal muestra una elegancia que solo se encuentra en lo más profundo del ser de la persona. Quien no vive en armonía con sus ideas, con sus pensamientos y emociones, quien no sabe lo que quiere no obra como debe, es incapaz de canalizar la riqueza afectiva de su ser, siembra el rencor y la desconfianza en los suyos y en los demás, busca aparentar lo que no es; quien es incapaz de llevar a la práctica las ideas lúcidas que surgen de lo más profundo del corazón y de tomar decisiones de manera inteligente, ese no puede ser elegante porque no es bueno ni dueño de sí mismo. La elegancia hay que moldearla, educarla y adecuarla a cada ocasión, pues es el atributo de ser excepcionalmente eficaz y sencillo.

¿Cómo se consigue esto? Primero, creyendo firmemente en la educación y en la profesión docente; segundo, contando con personas que cumplen con creces con estas características; $y$, tercero, dando a nuestros estudiantes un minuto de paz para reflexionar, compartir, ayudar, aprender.

En definitiva, podríamos decir, con el poeta Salinas (1982), que de cada estudiante buscamos que desarrolle su mejor tú. Y para desarrollar su mejor tú, además de las tres características anteriores (ser buena persona, ser educado y ser íntegro/elegante), la persona debe desarrollar y tener en equilibrio mente, corazón y manos. Esto es, una cabeza de hielo, un corazón de fuego y unos brazos de hierro. Estos tres elementos bien ordenados forman el eje de una personalidad fuerte y madura que únicamente será posible formar si docentes y discentes trabajan juntos en ese proceso conocido como aprender a aprender (Echeita y Sandoval, 2002; Messiou et al., 2014; Ocampo, 2018). Es decir, los profesores han de preguntarse qué es lo que quieren que aprendan sus estudiantes y cuál es la forma en la que les es más fácil aprender. Y, como estudiantes, han de tratar de averiguar qué es lo que uno hace habitualmente para aprender y cómo se puede mejorar (Jiménez, 2010, 2012; Acaso, 2013; Rodríguez-García, Hinojo y Ágreda, 2017).

Pero estas son palabras vacías si nadie nos enseña antes a ponerlo en práctica, si no intentamos hallar formas y procesos para que el acto educativo conduzca a los educandos al éxito, evite el fracaso y optimice el tiempo de todos los agentes implicados (Duque, Fisas y Valls, 2004; Martín y Jiménez, 2013; Castro, Gómez y Macazaga, 2014; Álvarez y Osoro, 2014).

Está claro que el objetivo de cualquier sistema educativo es potenciar el aprendizaje tanto de contenidos como de procedimientos para elaborar discursos propios y diseñar actuaciones para lograr que el estudiante maximice su tiempo de estudio en todos los ámbitos en los que se desenvuelve. 
Aprender a aprender es un desafío de la sociedad actual y, para ello, es preciso desarrollar habilidades que convierten a los estudiantes en aprendices cualificados y con un dominio cognitivo que facilite su continuo aprendizaje. En palabras de Nisbet y Suckmith (1986), el conocimiento más importante es el conocimiento de sí mismo y el aprendizaje más importante es el aprender a aprender. Esto último exige, pues, desarrollar habilidades metacognitivas que implican, a su vez, un conocimiento sobre el propio funcionamiento psicológico y el control efectivo del mismo. Cuando un estudiante conoce los procesos que tiene que activar a lo largo del aprendizaje y los mecanismos de control adecuados para regularlo, se puede decir que es autónomo y que tiene en sus manos el control del aprendizaje (García, Sánchez y Marenco, 2016; Casafont y Casas, 2017). Ese aprendizaje válido para todos y que podrá llevar a cabo a lo largo de toda la vida.

Todos los aspectos a los que venimos aludiendo son el resultado de la gran producción científica que se viene desarrollando a lo largo de los últimos años. Este hecho ha dado lugar a la indización de los mismos en bases de datos bibliográficas automatizadas que requieren el uso de la bibliometría y la generación de indicadores para medir los resultados de la actividad científico-investigadora. Aprovechando las posibilidades que nos ofrece la bibliometría y puesto que este año se celebra el 25 aniversario de la Declaración de Salamanca y marco de acción para las necesidades educativas especiales, nos surgió la inquietud de estudiar y analizar la producción científica publicada en español en torno a la educación inclusiva, utilizando como fuente de información los artículos publicados en la base de datos bibliográfica Scopus en el periodo 1994-2019, con el propósito de ofrecer una visión del estado de la investigación al respecto, a lo largo de este periodo. Las preguntas que nos planteamos fueron: ¿ En qué momento se encuentra la investigación sobre la educación inclusiva? ¿Quién desarrolla esos trabajos? ¿Cuál es el objeto de su interés? ¿Se han producido cambios en torno a la inclusión o se ha producido su estancamiento? ¿Qué dificultades existen? ¿Qué retos quedan por cumplir?

En suma, nuestro propósito aquí es conocer cuál ha sido la evolución de la educación inclusiva como objeto de investigación, para lo cual se tomó como referencia la producción científica durante el tiempo transcurrido desde la Declaración de Salamanca, de modo que podamos valorar qué retos son los que nos quedan por cumplir y así poder orientar todas las acciones y esfuerzos en esta dirección.

\section{Metodología}

Para la consecución de nuestro objetivo principal se decidió realizar un análisis bibliométrico de la producción científica sobre educación inclusiva generada desde que se aprobó la Declaración de Salamanca, 
en 1994, hasta la actualidad. Dicho análisis es un método documental que permite examinar la naturaleza y evolución de la literatura científica con base en una serie de indicadores, como son los propios documentos científicos, pero también los grupos que los producen y los consumen (González de Dios, Moya y Mateos, 1997) mediante la identificación de patrones de publicación, de colaboración y de impacto en términos de citación (Madrid et al., 2017).

\section{Selección de la muestra}

La muestra para el estudio la conformaron los artículos científicos publicados sobre educación inclusiva en los últimos veinticinco años y en español. La elección de la base de datos Scopus (Elsevier), como fuente para la recuperación de información científica sobre la temática elegida, se debe a dos motivos concretos: por un lado, a que en esta base de datos hay una presencia importante de trabajos publicados de ciencias sociales, ámbito al que pertenecen las ciencias de la educación; y, por otro, porque el número de revistas indexadas que se publican en español también es significativo.

Para la recuperación de los artículos científicos se utilizó como criterio de búsqueda el título del artículo. De este modo recuperamos aquellas publicaciones que toman la educación inclusiva como elemento central de estudio. En resumen, se aplicaron los delimitadores que se detallan en la tabla 1.

Tabla 1.

Criterios aplicados para la realización del estudio

\begin{tabular}{ll}
\hline Base de datos & Scopus \\
\hline Periodo & $1994-2019$ \\
\hline Tipología documental & Artículos cientíicos \\
\hline Idioma & Español \\
\hline Criterio de búsqueda & Título del artículo \\
\hline
\end{tabular}

Fuente: elaboración propia.

Para la localización de los artículos en la base de datos Scopus se utilizaron aquellos descriptores o términos de búsqueda que vienen a describir mejor el tema objeto de estudio: educación inclusiva, educación integradora, educación especial, necesidades educativas especiales, atención a la diversidad, educación para todos y necesidades específicas de apoyo educativo. Asimismo, se emplearon ecuaciones de búsqueda resultantes de la combinación de algunos de estos descriptores, por ejemplo: ["educación especial" AND integración] o ["Atención a la diversidad" AND Educación]. 
Los descriptores se introdujeron en la ventanilla de búsqueda en inglés, ya que en Scopus los documentos se encuentran indizados en este idioma. Una vez recuperados todos los artículos científicos, se delimitaron los resultados a aquellos publicados en español, lo que incluye trabajos editados en España y en países de América Latina, principalmente (tabla 2).

Tabla 2.

Número de resultados recuperados en función de los descriptores utilizados

\begin{tabular}{lcc}
\hline \multicolumn{1}{c}{ Descriptores } & $\begin{array}{c}\text { Total de resultados } \\
\text { recuperados }\end{array}$ & $\begin{array}{c}\text { Resultados } \\
\text { recuperados } \\
\text { publicados en español }\end{array}$ \\
\hline "Inclusive education" & 941 & 39 \\
\hline "Integrative education" & 5 & 1 \\
\hline "Special education" AND integration & 12 & 1 \\
\hline "Special education" AND inclusion & 50 & 0 \\
\hline "Special education needs" & 46 & 1 \\
\hline "Attention to diversity" AND education & 6 & 4 \\
\hline "Education for All" & 186 & 0 \\
\hline "Special Needs Education" & 62 & 4 \\
\hline
\end{tabular}

Fuente: elaboración propia.

En total, se recuperaron 50 trabajos que al depurarlos de duplicidades dio como resultado una muestra final de 48 artículos científicos publicados sobre la materia objeto de estudio, desde 1994 hasta la actualidad, y en español.

\section{Recolección y análisis de datos}

El proceso de búsqueda y recuperación de los trabajos científicos se desarrolló durante los meses de febrero y marzo de 2019. El tratamiento de las 48 referencias bibliográficas recuperadas y de los datos extraídos de estas se realizó mediante el gestor Refworks y el programa Excel.

Con el fin de hacer un estudio comparativo de la producción científica recuperada, se seleccionaron tres parámetros que permitieron analizar y categorizar los resultados recuperados: autoría, revista y artículo. A su vez, para cada uno de estos parámetros se identificó una serie de indicadores, tal como se muestra en la tabla 3. 
Tabla 3.

Parámetros e indicadores seleccionados

\begin{tabular}{|c|c|c|}
\hline Parámetros & \multicolumn{2}{|c|}{ Indicadores } \\
\hline \multirow{4}{*}{ Autor } & \multirow{3}{*}{ Afiliación } & Tipo de institución \\
\hline & & $\begin{array}{l}\text { Localización geográfica de las } \\
\text { instituciones }\end{array}$ \\
\hline & & $\begin{array}{l}\text { Naturaleza de la publicación } \\
\text { según la procedencia institucio- } \\
\text { nal de los autores }\end{array}$ \\
\hline & $\begin{array}{l}\text { N.. de autores que firman el } \\
\text { artículo }\end{array}$ & \\
\hline \multirow{3}{*}{ Revista } & País de publicación & \\
\hline & Tipo de edición (open access) & \\
\hline & Posicionamiento e impacto & \\
\hline \multirow{3}{*}{ Artículo } & Fecha de publicación & \\
\hline & N. ${ }^{\circ}$ de citas que han recibido & \\
\hline & Descriptores asignados & \\
\hline
\end{tabular}

Fuente: elaboración propia.

El parámetro "Autoría" nos dio a conocer la afiliación institucional de los responsables de los distintos trabajos recuperados sobre educación inclusiva, de modo que fue posible identificar el tipo de instituciones donde se elaboran estudios sobre la temática que nos interesa, así como su origen geográfico. También, determinamos si los trabajos se realizaron con carácter interuniversitario y/o internacional. Por último, atendiendo al número de autores que firman el artículo, comprobamos si los trabajos fueron elaborados por uno o varios investigadores.

El segundo de los parámetros, "Revista", nos facilitó identificar el país donde se editan las revistas en las que se han publicado los trabajos recuperados. Además, analizamos si son de fácil acceso y consulta al distinguir entre aquellas revistas que siguen los cánones del Open Access y las que no. Igualmente, consideramos aspectos como el posicionamiento e impacto de la revista según el indicador Scimago Journal Rank, que sirve para clasificar aquellas revistas cuyos trabajos se encuentran indizados en Scopus.

El tercer parámetro, "Artículo", tuvo como objetivo poner de relieve la fecha en la que fueron publicados los trabajos dentro del periodo cronológico seleccionado, así como el número de veces que han sido citados en otros estudios posteriores. Por último, identificamos los descriptores asignados a estos estudios que facilitan su posterior recuperación. 


\section{Resultados}

Se presentan, a continuación, los principales resultados del análisis bibliométrico efectuado sobre la producción científica recuperada. Para una mejor comprensión de estos, se muestran organizados en función de los tres parámetros anteriormente señalados: "Autoría", "Revista" y "Artículo".

\section{Parámetro "Autoría"}

\section{Afiliación de los autores}

Del total de 39 instituciones en las que desarrollan su trabajo, los autores de los artículos publicados sobre educación inclusiva, 87,1 \% corresponde a universidades; mientras que 10,2 \% son centros de estudios como el National Center of Scientific and Technological Research, de Mali, y el Centro de Estudios Latinoamericanos de Educación Inclusiva, de Chile. Asimismo, se ha localizado un artículo elaborado por el servicio de fisioterapia de un centro escolar de educación especial de Málaga, así como otro trabajo -en coautoría- por un profesional de la Escuela Oficial de Idiomas de la misma ciudad.

En cuanto a la ubicación geográfica de las instituciones, 64,10 \% se encuentran en España; mientras que el resto se divide entre países como Colombia (15,38\%), Chile y México con una representación igualitaria de 5,12 \%, y en Cuba, Ecuador, Estados Unidos y Mali, con 2,56 \% cada uno (figura 1).

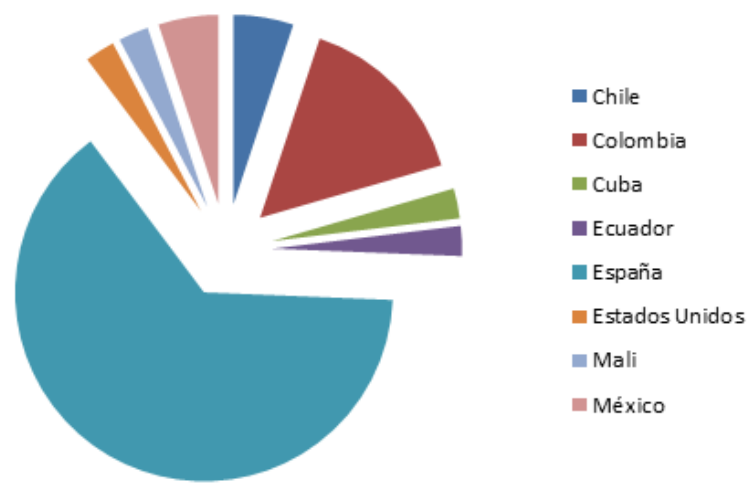

Figura 1. Número de instituciones por país

Fuente: elaboración propia

Por otra parte, del total de trabajos presentados (48), 29,16 \% se han elaborado con carácter interuniversitario. De estos, solo 42,85\% se han realizado con carácter internacional al participar personal docente e investigador 
de universidades de diferentes países, lo que da muestra de la preocupación por el estudio de la educación inclusiva en diversos espacios. De esos casos, se destaca el artículo publicado entre la University of Notre Dame, de Estados Unidos, y el National Center of Scientific and Technological Research, de Mali (figura 2).

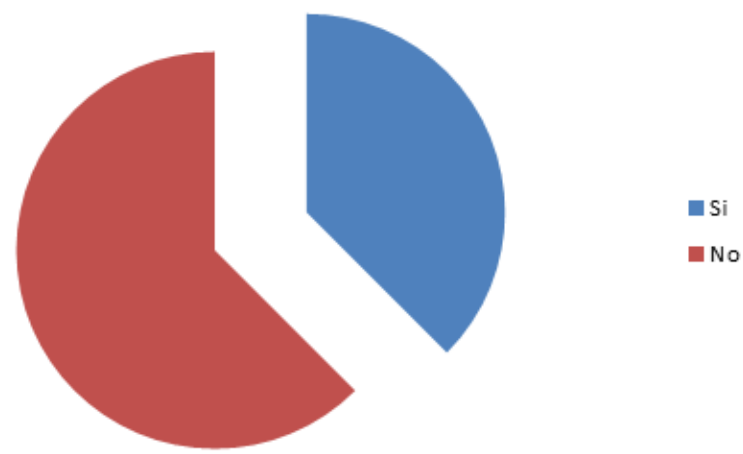

Figura 2. Número de trabajos elaborados con carácter interuniversitario

Fuente: elaboración propia

En cuanto a los departamentos universitarios y áreas de conocimiento a las que pertenecen los autores de los trabajos, los datos localizados no permiten cuantificar con exactitud cuál es su representación; sin embargo, sí podemos concluir que se circunscriben a dos ámbitos principalmente: la educación y la psicología. En el primer caso, los autores pertenecen a departamentos universitarios de Didáctica y Organización Educativa; en el segundo, los responsables de los artículos desarrollan su labor en la universidad en departamentos denominados bien de la psicología evolutiva y de la educación bien de personalidad, evaluación y tratamiento psicológico.

Con una representación inferior se hallarían los estudios de especialistas en medicina y en sociología.

\section{Número de autores}

Como viene siendo habitual en el ámbito de las Ciencias Sociales donde se ubican las Ciencias de la Educación, 39,58 \% de los trabajos localizados han sido elaborados por un solo autor, y su número decrece a medida que aumenta el número de responsables del estudio, como se puede observar en la figura 3.

Esta práctica compartida por la mayoría de los investigadores en el ámbito de las Ciencias Sociales en las que se ubica la disciplina de la educación, de trabajar de manera individual o en grupos reducidos se está viendo 
transformada ya que cuanto más recientes son los artículos, observamos que aumenta ligeramente el número de responsables del estudio al trabajar en equipos de investigación y no de manera aislada.

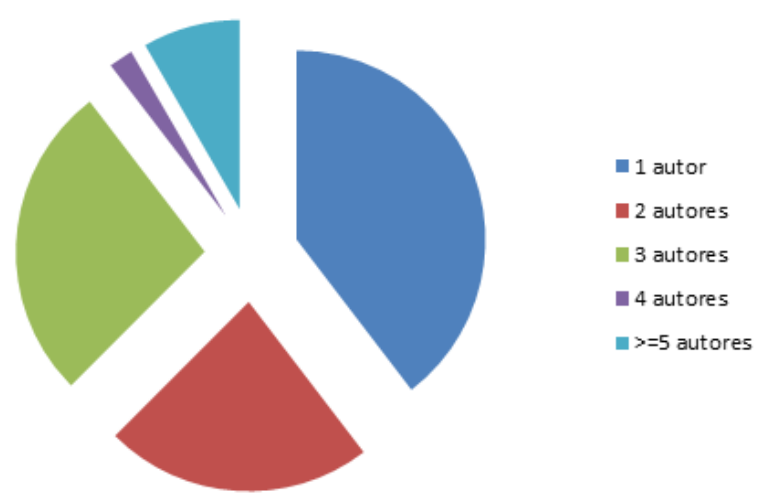

Figura 3. Número de autores que publican los artículos

Fuente: elaboración propia

\section{Parámetro "Revista"}

Las revistas donde se han difundido los trabajos que constituyen la muestra de este estudio conforman un grupo de 21 publicaciones editadas por distintas instituciones entre las que sobresalen las de carácter universitario (61\%), aunque también podemos encontrar algunas cuyos responsables son asociaciones profesionales y fundaciones (39\%).

Estas publicaciones se enmarcan en el contexto de la educación, la psicología y la medicina, lo que las sitúa en la línea del origen disciplinar de los autores de los estudios en materia de educación inclusiva.

En la tabla 4 se muestra el nombre de estas publicaciones, así como los responsables de su edición.

\section{Tabla 4.}

Revistas donde se publicaron los artículos y responsables de su edición

\begin{tabular}{ll}
\hline \multicolumn{1}{c}{ Nombre de la revista } & \multicolumn{1}{c}{ Editor } \\
\hline Bordón & Sociedad Española de Pedagogía \\
\hline Development in Practice & Carfax Publishing Ltd. \\
\hline Educación XXl & UNED \\
\hline Educación Médica & Fundación Educación Médica (EducMec) \\
\hline
\end{tabular}




\begin{tabular}{|c|c|}
\hline Nombre de la revista & Editor \\
\hline Education Policy Analysis Archives & Arizona State University (USA) \\
\hline Estudios Pedagógicos & Universidad Austral de Chile \\
\hline Estudios sobre Educación & Universidad de Navarra \\
\hline Formación Universitaria & Centro de Información Tecnológica \\
\hline $\begin{array}{l}\text { Opción. Revista de Ciencias Humanas y } \\
\text { Sociales }\end{array}$ & Universidad del Zulia \\
\hline Perfiles Educativos & $\begin{array}{l}\text { Universidad Nacional Autónoma de } \\
\text { México (UNAM) }\end{array}$ \\
\hline $\begin{array}{l}\text { Profesorado. Revista de Currículum y } \\
\text { Formación del Profesorado }\end{array}$ & $\begin{array}{l}\text { Universidad de Granada. Grupo de } \\
\text { investigación FORCE }\end{array}$ \\
\hline Psicología Escolar e Educacional & $\begin{array}{l}\text { Associaçao Brasileira de Psicología Escolar } \\
\text { e Educacional }\end{array}$ \\
\hline Revista Complutense de Educación & Universidad Complutense de Madrid \\
\hline Revista de Educación & Ministerio de Educación, Cultura y Deporte \\
\hline $\begin{array}{l}\text { Revista Electrónica de Investigación } \\
\text { Educativa }\end{array}$ & $\begin{array}{l}\text { Educativo Univ. Autónoma de Baja } \\
\text { California. Instituto de Investigación y } \\
\text { Desarrollo }\end{array}$ \\
\hline $\begin{array}{l}\text { Revista electrónica de Investigación y } \\
\text { Evaluación Educativa }\end{array}$ & $\begin{array}{l}\text { Universidad de Valencia. Dpto. Métodos de } \\
\text { Investigación y Diagnóstico en Educación }\end{array}$ \\
\hline $\begin{array}{l}\text { Revista Ensaio: Avaliaçao e Políticas } \\
\text { Públicas em Educaçao }\end{array}$ & Fundaçao Cesgranrio \\
\hline Revista Espacios & $\begin{array}{l}\text { Asociación de profesionales y técnicos de } \\
\text { Conicit }\end{array}$ \\
\hline $\begin{array}{l}\text { Revista Española de Orientación y } \\
\text { Psicopedagogía }\end{array}$ & $\begin{array}{l}\text { Asociación Española de Orientación y } \\
\text { Psicopedagogía }\end{array}$ \\
\hline Revista Facultad de Medicina & Universidad Nacional de Colombia \\
\hline Revista Fuentes & $\begin{array}{l}\text { Universidad de Sevilla. Facultad Ciencias } \\
\text { de la Educación }\end{array}$ \\
\hline
\end{tabular}

Fuente: elaboración propia.

\section{País de publicación}

Si atendemos al país de publicación de las revistas, podemos comprobar cómo estas proceden de España, América Latina (principalmente Venezuela, Colombia, México y Chile), así como de otros países de América del Sur, como Brasil, y de América del Norte, como Estados Unidos (figura 4). 


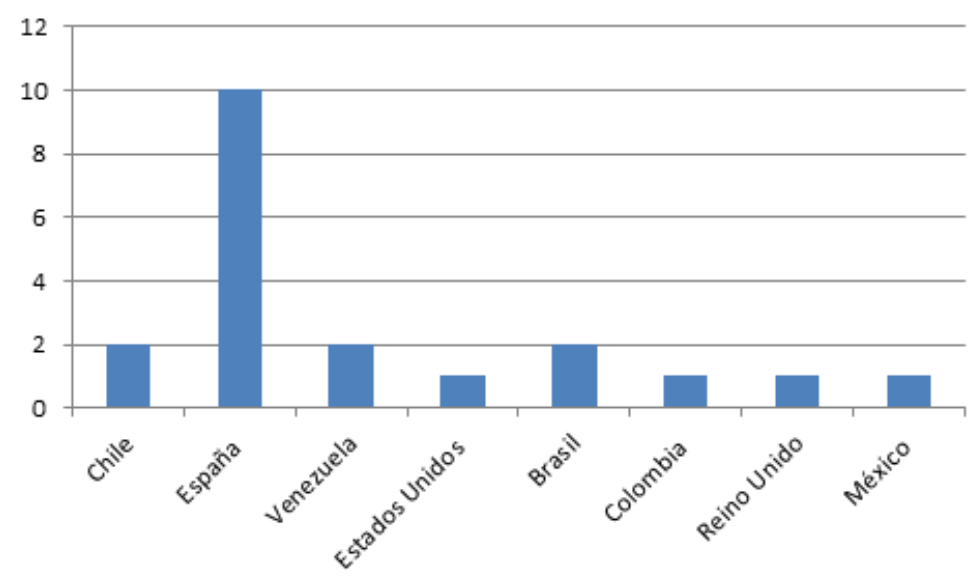

Figura 4. País de publicación de las revistas

Fuente: elaboración propia

\section{Acceso a las publicaciones científicas}

El acceso a las publicaciones constituye uno de los elementos fundamentales a la hora de difundir los estudios, y a ello contribuyen de manera especial las revistas que se editan siguiendo los postulados del acceso abierto, u open access. Este movimiento internacional permite a cualquier usuario acceder de forma libre y gratuita a la literatura científica, académica y cultural disponible en internet. Bases de datos científicas como Scopus y la Web of Science, entre otras, tienen indexadas revistas editadas en acceso abierto, muchas de las cuales poseen factor de impacto. Ello permite una mayor visibilidad y difusión de los resultados de investigación al facilitar su consulta inmediata y la posibilidad de que los trabajos científicos sean citados por un mayor número de investigadores.

En este sentido hemos querido poner de relieve cuántos de los trabajos localizados se editan en este tipo de revistas. Para ello tuvimos en consideración aquellas publicaciones editadas a partir de 2001, año en el que se firma la Declaración de Budapest, que pone los cimientos de la difusión en acceso abierto de las revistas científicas. De este modo, pudimos comprobar cómo del total de artículos publicados entre 20012019 y que coinciden además con el total de la muestra recuperada, únicamente $29,16 \%$ se encuentran accesibles en revistas que cumplen los cánones del open Access (figura 5). 


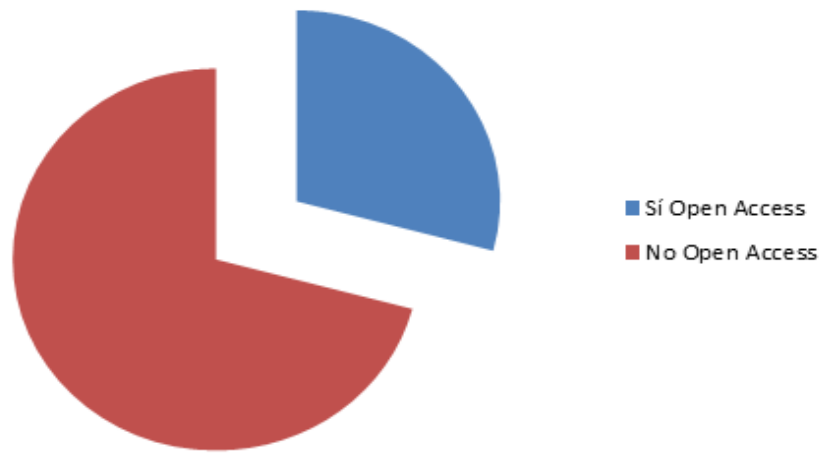

Figura 5. Revistas publicadas en acceso abierto

Fuente: elaboración propia.

\section{Posicionamiento e impacto de la revista}

El Scimago Journal Rank (SIR) es el indicador de medición desarrollado a partir de la información científica contenida en la base de datos Scopus y que establece la calidad de las revistas indexadas en ella, a partir del recuento del número de citas obtenidas por cada publicación. El sJR otorga un peso determinado a las citas que recibe una revista en función del área científica a la que se encuentra vinculada y la relevancia de las revistas citantes.

Los datos recogidos relativos a la posición que ocupan las revistas donde se han publicado los artículos que conforman la muestra así como su índice SJR corresponden a 2017, dado que es la última fecha sobre la que este indicador bibliométrico ofrecía información en el momento de realizar nuestro estudio.

Por lo que respecta a las áreas temáticas a las que se encuentran asociadas las revistas hemos de indicar que prácticamente todas se hallan ligadas a la de educación. En cuanto a la posición que ocupan las publicaciones, tal como se muestra en la figura $6,20,83 \%$ se sitúan en el tercer cuartil; $12,5 \%$, en el segundo; $8,33 \%$, en el cuarto, y $2,08 \%$, en el primero. Esto significa que las revistas en las que se han difundido los trabajos sobre educación inclusiva no tienen la relevancia deseada dentro del campo científico al que se encuentran vinculadas. 


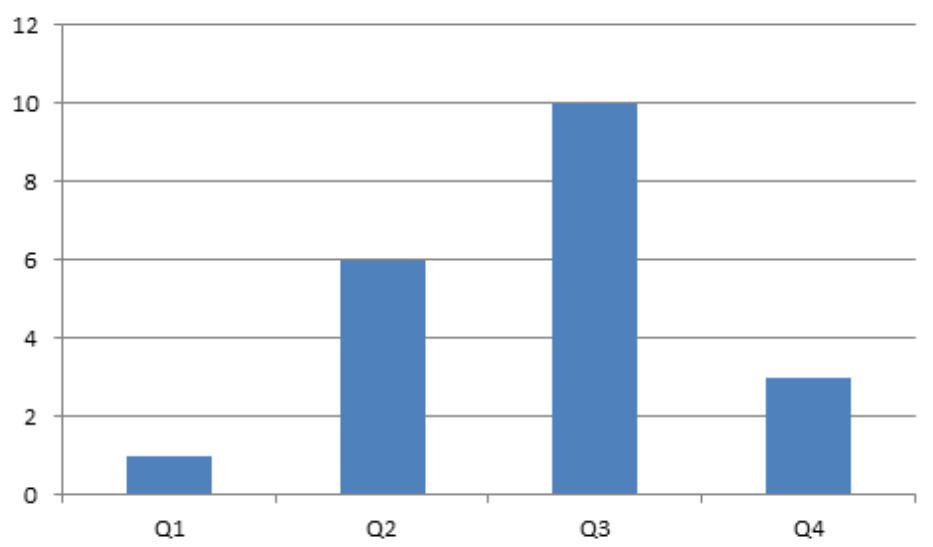

Figura 6. Cuartil en el que se ubican las revistas en el sJR

Fuente: elaboración propia

Uno de los indicadores bibliométricos más importantes es el factor de impacto que posee una revista. Por lo que, en cuanto al impacto de las revistas indexadas en la base de datos Scopus, es el índice SJR la herramienta utilizada para medirlo. Este indicador evalúa el impacto de una publicación científica combinando el número de citas recibidas con la influencia de las publicaciones que la citan durante un periodo de tiempo determinado. Así, cuanto mayor sea el índice de impacto de una revista mayor será su relevancia en el campo científico en el que se ubique.

En la figura 7 se muestra cómo $35 \%$ de las revistas que publican artículos sobre educación inclusiva cuentan con un índice SIR de entre $0,31-0,40$, seguido de $30 \%$ de revistas que cuentan con un índice situado entre 0,21 y 0,30 .
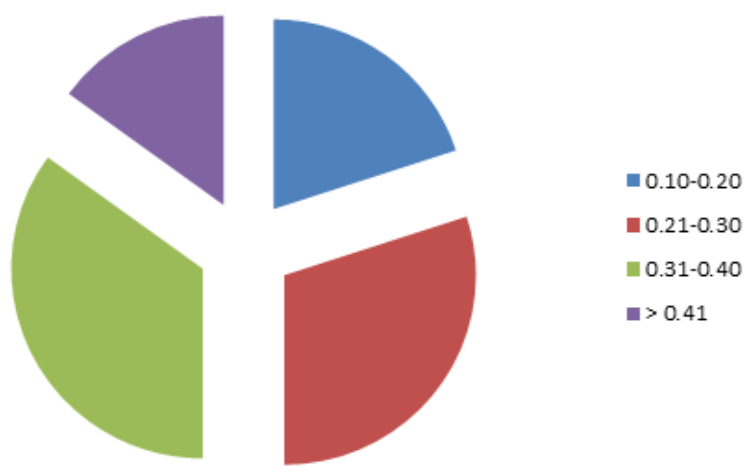

Figura 7. Índice sJR de las revistas 


\section{Parámetro "Artículo"}

\section{Fecha de publicación}

Si atendemos a la fecha de publicación de los artículos elaborados sobre educación inclusiva en los últimos veinticinco años, se observa en la figura 8 cómo el mayor número se produce en la última década con crecimientos significativos de la producción científica en 2013 y 2018. Posiblemente este hecho venga precedido, por un lado, por los cambios introducidos en las normativas legales de los diferentes países donde se pone de manifiesto, entre otras cuestiones, el derecho a una educación de calidad para todo el alumnado y a lo largo de toda la vida, a la equidad como garantía de la igualdad de oportunidades, a la inclusión educativa, a la igualdad y a la no discriminación para desarrollar armónicamente todas las facultades del ser humano; $y$, por otro lado, por los objetivos marcados en la agenda Educación 2030, para la consecución del Objetivo de Desarrollo Sostenible 4: "Garantizar una educación inclusiva y equitativa de calidad y promover oportunidades de aprendizaje permanente para todos" (Unesco, 2015), donde se pone el acento, además de en las cuestiones anteriores, en poner en práctica procesos de mejora en las comunidades educativas, en desarrollar sistemas educativos más inclusivos y en la formación del profesorado como garante de equidad y de calidad.

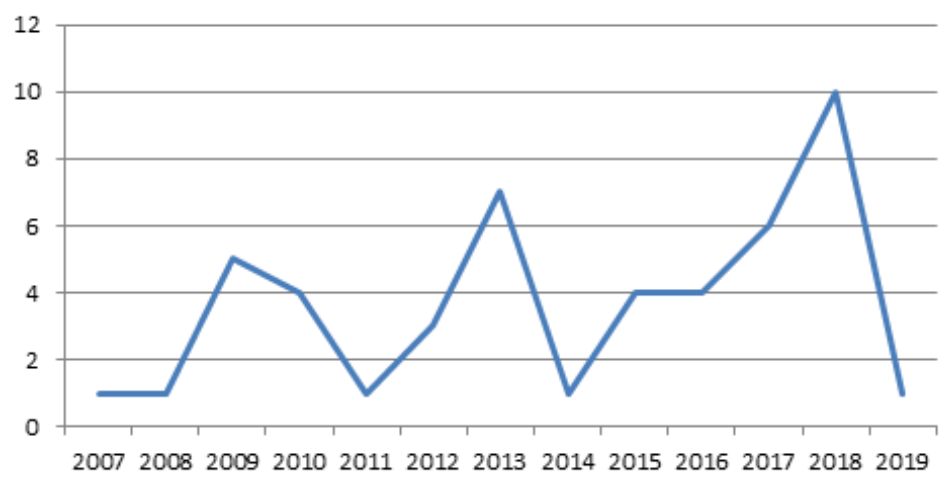

Figura 8. Fecha de publicación de los artículos

Fuente: elaboración propia

\section{Número de citas recibidas}

El impacto de un artículo científico se mide a través de las citas que recibe. Cuanto mayor sea su número, mayor relevancia se entiende que tiene dicho trabajo en el campo disciplinar al que se asocia. La base de datos 
Scopus es una de las herramientas bibliográficas más utilizadas a nivel internacional para conocer el número de citas que ha recibido un artículo publicado en las revistas indexadas en la base de datos.

El análisis cuantitativo de las publicaciones relativas a educación inclusiva que constituyen el objeto de este estudio nos indica que una gran parte ha recibido un número inferior a cuatro citas, cuestión que denota la escasa trascendencia de los trabajos localizados. No obstante, el reconocimiento de la relevancia de un artículo científico es directamente proporcional al tiempo transcurrido desde su publicación, por lo que cabe esperar que aumente el número de citas que muchos de estos trabajos han recibido (figura 9).

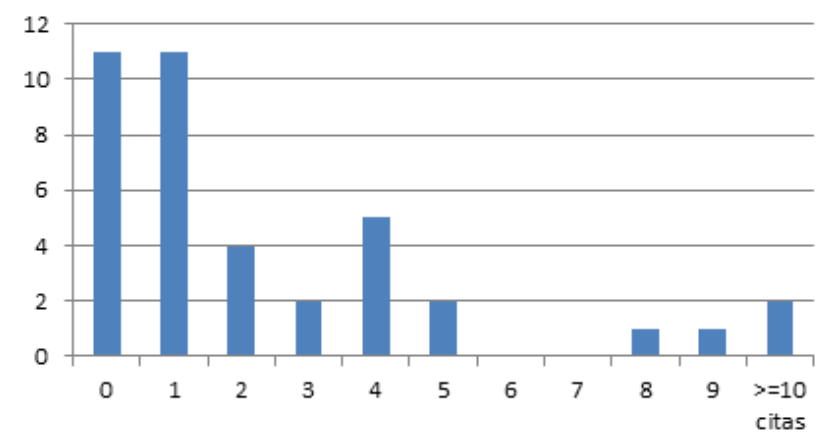

Figura 9. Número de citas recibidas

Fuente: elaboración propia

\section{Descriptores asignados a los artículos}

Dado que este es un estudio bibliométrico y, por tanto, tiene carácter cuantitativo, hemos querido hacer un análisis somero del contenido de los artículos mediante el conteo de los descriptores que sus autores les han asignado. De este modo, del total de la muestra - 48 artículos científicos-se extrajeron 143 descriptores que nos sirvieron, en primer lugar, para comprobar que los términos utilizados por los autores corresponden, en gran medida, con los que nosotros empleamos para realizar la consulta en Scopus y que, recordemos, eran: educación inclusiva, educación integradora, educación especial, necesidades educativas especiales, atención a la diversidad, educación para todos y necesidades específicas de apoyo educativo, inclusión e integración. En segundo lugar, su estudio nos permite señalar que la temática educación inclusiva se relaciona o complementa con otros aspectos como aprendizaje colaborativo, derechos humanos, buenas prácticas educativas, tecnologías de la información o formación del profesorado, principalmente. Siendo todos ellos aspectos que se englobarían, utilizando terminología empleada en la Declaración de 
Incheón para la Educación 2030 (Unesco, 2015), en una nueva visión de la educación cuyo objetivo prioritario es "transformar las vidas mediante la educación, reconociendo el importante papel que desempeña la educación como motor principal del desarrollo" (p. 7).

\section{Conclusiones}

Si bien es cierto que todo comenzó con el movimiento global a favor de la educación para todos iniciado en Jomtien (Tailandia), en 1990, es la Declaración de Salamanca aprobada hace ya 25 la que establece un antes y un después a nivel internacional en lo que hoy conocemos como educación inclusiva, dando lugar a un movimiento reivindicativo en pro de una educación para todos, que se ve ratificada posteriormente en Dakar (Senegal), en el año 2000, cuya pretensión última siempre ha sido impulsar progresos significativos en el ámbito de la educación.

A este respecto cabe destacar los cambios y avances importantes que se produjeron durante los primeros años en torno a la inclusión debido, en gran medida, a la influencia del movimiento integrador iniciado en los países nórdicos, a los movimientos en defensa de los derechos humanos y a la reivindicación permanente de los derechos de las minorías por parte de los movimientos asociativos, entre otros, que pusieron en cuestión la segregación. Posteriormente, entre 1995 y 2006, esta euforia inicial comienza a descender, provoca una acomodación de la situación y genera cierta inercia motivada por la etapa anterior, que traería consigo la pérdida progresiva de la homogeneidad propia de la enseñanza ordinaria; así, poco a poco se hace más perceptible la presencia de la diversidad en las aulas. Se podría afirmar que en esta etapa todos los esfuerzos se concentran en buscar la respuesta educativa más apropiada para esta nueva realidad, a través de la promulgación de leyes que establecieran medidas organizativas apropiadas para ofrecer una respuesta a la diversidad del alumnado presente, cada vez en mayor medida, en las aulas y centros educativos ordinarios (Tenti, 2008; Núñez, 2019). Hoy, esta situación de aparente inercia y estabilidad ha desaparecido, y se ha dado lugar a un periodo de estancamiento (e incluso se podría hablar de retroceso) con respecto a la inclusión, pese a que, en la actualidad, tanto las leyes como los discursos políticos e inclusivos están hoy más generalizados que nunca. Este estancamiento y retroceso es debido fundamentalmente al incumplimiento a lo largo de estos años de las propuestas inclusivas nacionales e internacionales que no han evolucionado como se esperaba.

A pesar de todos los esfuerzos realizados en el Foro Mundial sobre la Educación 2015, celebrado en Incheón (República de Corea), del 19 al 22 de mayo de 2015, se puso de manifiesto que, aunque se reconocían los esfuerzos efectuados, se observaba con gran preocupación que estábamos 
lejos de haber alcanzado la educación para todos (Preámbulo, punto 2, p. 6). Tal vez, la dificultad estriba en que superar esta situación requiere cambios sistémicos que afecten a todos los componentes del sistema educativo y a toda la sociedad, esto es, al currículo, a la formación del profesorado, a las políticas y prácticas escolares, a los estamentos sociales, políticos y culturales, etc., que rompan con las concepciones, rutinas e inercias que permanecen excesivamente arraigadas en las sociedades de todo el mundo (Blanco, 2008; Echeita, 2015).

Desde nuestro punto de vista y a la luz del análisis bibliográfico hecho sobre este tema, consideramos que, a pesar de que aún queda mucho camino por recorrer, también son numerosos los obstáculos sorteados y los avances conseguidos aunque la visibilidad de los mismos sea, aparentemente, a pequeña escala. Hemos de ser conscientes de que la inclusión y, por ende, la educación para todos no son un recorrido concluso ni exento de aspectos susceptibles de mejora, sino una experiencia que representa la meta y el sentido auténtico de la inclusión por constituir un puente capaz de cruzar fronteras, crear entendimiento y formar docentes comprometidos con los valores de la inclusión (Iglesias y Beltrán, 2012).

En nuestra opinión, y no obstante los vientos en contra que siempre soplan en torno a la inclusión, nos encontramos en un prometedor punto de partida que ha dado múltiples frutos, pero no en un punto de llegada. Las acciones llevadas a cabo tanto a nivel nacional como internacional han generado importantes logros, pero sigue siendo necesario continuar abordando los numerosos desafíos que quedan pendientes (Unesco, 2015), no exentos de obstáculos pero sí repletos de nuevos estímulos orientados a la acción, a la reflexión y al compromiso docente (Iglesias y Beltrán, 2012). Algunos de estos retos que hay que acometer tomando en consideración el análisis bibliométrico realizado de los artículos científicos publicados en revistas indexadas en Scopus, en lengua española sobre educación inclusiva a lo largo de estos 25 años, que a su vez dan respuesta a las preguntas que nos planteamos al inicio de este estudio, son los que a continuación se detallan:

» Resultan aún escasos los estudios efectuados en español sobre la materia objeto de estudio, habida cuenta del reducido número de artículos recuperados en la base de datos mencionada, durante el periodo examinado.

»En lo que respecta a los autores de estas investigaciones, cabe destacar que estos elaboran sus estudios de manera individual o en grupos de dos o tres investigadores lo que corresponde con la práctica habitual de los autores en el ámbito de las Ciencias Sociales. Además, la inmensa mayoría lleva a cabo su labor profesional en universidades mientras que son escasos los estudios desarrollados por personal procedente de centros especializados 
y/o asociaciones profesionales del ámbito educativo o del área de la psicología o de la medicina de la que proceden algunos estudios localizados. En el caso de las universidades, $64,10 \%$ de los artículos científicos recuperados han sido elaborados por instituciones académicas españolas, de las que entre ellas sobresale la Facultad de Educación de la Universidad de Sevilla.

» Llama la atención que cerca de un $30 \%$ de los artículos sea el resultado de colaboraciones interuniversitarias y que, dentro de estas, algunas se hayan elaborado entre instituciones académicas de países diferentes como la llevada a cabo por la University of Notre Dame, de Estados Unidos, y el National Center of Scientific and Technological Research, de Mali.

Las revistas en las que se publicaron los estudios se editan en su mayor parte en el contexto universitario, aunque algunas también se encuentran avaladas por asociaciones profesionales y fundaciones. Si atendemos al país en el que se publican, la mayoría son editadas en España y América Latina, lo que no sorprende habida cuenta de que uno de los criterios de selección era precisamente que los artículos hubieran sido publicados en español.

»En cuanto a las disciplinas científicas sobre las que se encuentran especializadas, coinciden con las áreas de conocimiento de los autores de los estudios, siendo estas la educación, la psicología y, en menor medida, la medicina.

» Son escasas aún las revistas que se publican siguiendo los cánones del acceso abierto (solo 29,16\%), lo que dificulta el acceso y visibilidad de los estudios realizados en materia de educación inclusiva.

» Respecto al posicionamiento de las publicaciones, solo un 2,08 \% se sitúa en el primer cuartil del ranking de Scimago y solo tres revistas consiguen tener un índice SIR superior a 0,5. Estos datos nos indican que las publicaciones en las que se han difundido los estudios sobre educación inclusiva no son todavía todo lo relevantes que fuera deseable en el ámbito de la educación.

» Dentro del periodo examinado, los artículos localizados fueron publicados sobre todo en la última década, aunque se acusan dos picos importantes de producción en 2013 y en 2018, cuestión que puede responder a los cambios introducidos en las normativas legales de los diferentes países y a los objetivos marcados en la agenda Educación 2030, para la consecución del Objetivo de Desarrollo Sostenible 4: "Garantizar una educación inclusiva y equitativa de calidad y promover oportunidades de aprendizaje permanente para todos" (Unesco, 2015), en todos los niveles, con iguales oportunidades, sin dejar a nadie atrás y a lo largo de toda la vida. 
» Del total de citas recibidas por los artículos analizados, el 56,41 \% recibió solo una cita o ninguna, lo que señala el escaso impacto que han tenido estos estudios en investigaciones desarrolladas posteriormente por otros especialistas en la materia.

»En cuanto a los descriptores asignados por los autores a sus trabajos, su estudio nos permite confirmar que la temática educación inclusiva se relaciona o complementa con otros aspectos como aprendizaje colaborativo, derechos humanos, buenas prácticas educativas, tecnologías de la información o formación del profesorado.

Y, desde el punto de vista del análisis del contenido de los 48 artículos analizados, las tareas, retos y desafíos que deberíamos abordar son:

» Dar una mayor visibilidad a las acciones llevadas a cabo en los centros o comunidades educativas, en las universidades, en las asociaciones a favor de una educación inclusiva y equitativa de calidad, promotora de oportunidades de aprendizaje permanente para todos (Arias, 2014; Azorín, 2017b; Boroel, Sánchez, Morales y Henríquez, 2018).

» Ampliar la red de vínculos o de colaboración, también denominadas redes de apoyo (Azorín, 2017a; Arnáiz, De Haro y Azorín, 2018) con otros centros, con otras universidades, con otras asociaciones e instituciones, con personas de diferentes orígenes culturales para poder considerar ideas, perspectivas y valores diferentes sobre asuntos tan importantes como la educación, capaces de traspasar fronteras nacionales e internacionales que en un momento dado puedan llegar a afectar a sus vidas.

» Consolidar a la comunidad educativa como impulsora de la inclusión. Se debe centrar la atención y los esfuerzos en formar profesorado inclusivo, reflexivo y comprometido con la educación. Para ello, se les ha de proporcionar una formación continua coherente con el modelo educativo que se quiere que los futuros maestros realicen (Albornoz, Silva y López, 2015; Colmenero, Pantoja y Pegalajar, 2015; González y Blanco, 2015; Boroel, Sánchez, Morales y Henríquez, 2018). Lograr este cometido y mantener la conexión con el otro solo será posible si se trabaja la emotividad que es uno de los hilos conductores que todos los seres humanos tienen en común (Shulman, 2005; Sharma, 2011; Iglesias, 2014, 2018). Un buen maestro inclusivo será aquel capaz de suscitar y transmitir emociones que se transformarán en motivaciones para los estudiantes.

» Crear capital humano (Carrillo et al., 2018). Para lograrlo, la educación debe ser progresivamente personalizada, basada en los seres humanos y en los valores, fundamentalmente, en el aprender a ser 
libre y responsable, y en la capacidad que cada persona posee para desarrollarse en plenitud (Gradaílle y Caride, 2016). En palabras de Luis de Lezama (2017), "la demanda es de un ser tremendamente capaz de mantener su capital ante la mutación, el cambio, la invasión y la devaluación del tener" (p. 23).

»Consolidar políticas inclusivas a todos los niveles y desarrollar sistemas educativos más inclusivos (Azorín, 2017b) para garantizar la equidad y la calidad, que reconozcan la diversidad como un valor y sean capaces de promover la inclusión y la participación en la educación desde la justicia social (Boroel, Sánchez, Morales y Henríquez, 2018).

A pesar de que las autoras somos conscientes de que el estudio presentado representa tan solo una parte de las investigaciones efectuadas en torno a la inclusión al habernos centrado en la producción científica publicada en lengua española en la base de datos bibliográfica Scopus; podemos concluir que en todas ellas se trasluce la misma visión de la educación que defiende la Declaración de Incheón (Unesco, 2015), que no es otra que "transformar las vidas mediante la educación, reconociendo el importante papel que desempeña la educación como motor principal del desarrollo" (p. 7). A este respecto, hacemos nuestras las palabras de Luis de Lezama (2017) cuando dice que:

En la educación es importante reconocer que tu conocimiento es participativo de los demás. Conocer a otros significa sabiduría. Conocerse a sí mismo es iluminación. Pero deja de producirse cuando pierdes rigor y la inteligencia no es capaz de crear humildad. [...] Tu humildad, la gran estima por las capacidades de los demás, hará brillar más tu victoria. (pp. 82-83)

\section{Referencias}

Acaso López-Bosch, M. (2013). rEDUvolution: Hacer la revolución en la educación. Barcelona: Paidós.

Aiello, P. y Sharma, U. (2018). Improving intentions to teach in inclusive classrooms: the impact of teacher education courses on future Learning Support Teachers. Form@re-Open Journal per la formazione in rete, 18(1), 207-219. Dol: http://dx.doi.org/10.13128/formare-22605

Albornoz, N., Silva, N. y López, M. (2015). Escuchando a los niños: Significados sobre aprendizaje y participación como ejes centrales de los procesos de inclusión educativa en un estudio en escuelas públicas en Chile. Estudios Pedagógicos, 41 (especial), 81-96. Dol: http://dx.doi. org/10.4067/S0718-07052015000300006 
Álvarez, C. y Osoro, J.M. (2014). Colaboración universidad-escuela para la innovación escolar. Una investigación-acción en proceso. Innovación Educativa, 24, 215-227.

Arias Beatón, G. (2014). Una educación para todos y de calidad, una máxima ética y política. Psicología Escolar e Educacional, 18(2), 359-368. DOI: http://dx.doi.org/10.1590/2175-3539/2014/0182870

Arnaiz, P., De Haro, R. y Azorín, C.M. (2018). Redes de apoyo y colaboración para la a mejora de la educación inclusiva. Profesorado, 22(2), 7-27

Azorín Abellán, C.M. (2017a). Una mirada desde los organismos internacionales a la educación para todos. Opción, 33(83), 203-228.

Azorín Abellán, C.M. (2017b). Análisis de instrumentos sobre educación inclusiva y atención a la diversidad. Revista Complutense de Educación, 28(4), 1043-1060. DOI: http://dx.doi.org/10.5209/RCED.51343

Blanco Guijarro, M.R. (2008). Haciendo efectivo el derecho a una educación de calidad sin exclusiones. Revista Colombiana de Educación, 54, 14-35.

Boroel, B.I., Sánchez, J., Morales, K.D. y Henríquez, P.S. (2018). Educación exitosa para todos: La tutoría como proceso de acompañamiento escolar desde la mirada de la equidad educativa. Revista Fuentes, 20(2), 91-104. DOI: 10.12795/revistafuentes.2018.v20.i2.06

Carrillo, S.M., Forgiony, J.O., Rivera, D.A., Bonilla, N.J., Montanchez, M.L. y Alarcón, M.F. (2018). Prácticas pedagógicas frente a la educación inclusiva desde la perspectiva del docente. Espacios, 39(17), 15.

Casafont, R. y Casas, L. (2017). Educarnos para educar. Neuroaprendizaje para transformar la educación. Barcelona: Paidós.

Castro, M., Gómez, A y Macazaga, A.M. (2014). Aprendizaje dialógico y grupos interactivos en educación física. Retos: Nuevas tendencias en educación física, deporte y recreación, 25, 174-179.

Colmenero, M.J., Pantoja, A. y Pegalajar, M.C. (2015). Percepciones sobre atención a la diversidad en la formación inicial del profesorado de Educación Secundaria. Revista Complutense de Educación, 26(1), 101120. Dol: https://dialnet.unirioja.es/servlet/articulo?codigo $=5754612$

De Lezama, L. (2017). La escuela del futuro. El sistema educativo del colegio Santa María la Blanca. Madrid: PPC.

Diario Oficial de las Comunidades Europeas (2000). Carta de los derechos fundamentales de la Unión Europea (2000/C 364/01). Recuperado de http://www.europarl.europa.eu/charter/pdf/text_es.pdf

Duque, E., Fisas, M. y Valls, R. (2004). Dialogar y transformar. Pedagogía crítica del siglo XXI. Barcelona: Graó.

Echeita, G. y Sandoval, M. (2002). Educación inclusiva o educación sin exclusiones. Revista de Educación, 327, 31-48. 
Echeita, G. y Verdugo, M.A. (2004). La Declaración de Salamanca sobre necesidades educativas especiales 10 años después. Valoración y prospectiva. Salamanca: INICO.

Echeita Sarrionandia, G. (2015). ¡Que 30 años no es nada! El proceso de inclusión educativa en España del alumnado considerado con necesidades educativas especiales. "Quien bien te quiere te hará Ilorar". En M.A. Verdugo, T. Nieto, M. Crespo, D. Velázquez, E. Vicente y V. Guillén (dirs.), IX Jornadas Científicas Internacionales de Investigación sobre Personas con Discapacidad (pp. 1-13). Salamanca: INICO.

García, M.L., Sánchez, M. del R. y Marenco, D.E. (2016). Disfrutar aprendiendo. Propuestas didácticas imaginativas para la enseñanza inicial. Barcelona: Octaedro.

García-Barrera, A. (2017). Las necesidades educativas especiales: Un lastre conceptual para la inclusión educativa en España. Ensaio, 25(96), 721-742.

García Rubio, J. (2017). Evaluación legislativa de la educación inclusiva en España. Revista Nacional e Internacional de Educación Inclusiva, 10(1), 251-264.

González, Á.L. y Blanco, M. (2015). Formación del profesorado de educación inclusiva: reto docente de la educación especial. Opción, 31(edición especial 3), 582-604.

González de Dios, J., Moya, M. y Mateos Hernández, M.A. (1997). Indicadores bibliométricos: características y limitaciones en el análisis de la actividad científica. Anales Españoles de Pediatría, 47, 235-244. Recuperado de https://www.aeped.es/sites/default/files/anales/47-3-3.pdf

Gradaílle, R. y Caride, J.A. (2016). La Accesibilidad en las realidades de la vida cotidiana: La pedagogía social en la construcción del derecho a una educación inclusiva. Education Policy Analysis Archives, 24. DOI: http://dx.doi.org/10.14507/epaa.24.2458

Hernández, A. e Iglesias, A. (2017). La importancia de las competencias digitales e informacionales para el desarrollo de una escuela intercultural. Revista Interacçoes, 13(43), 205-232. DOI: https://doi. org/10.25755/int.12038

Iglesias, A. y Beltrán, F. (2012). Practicum sin fronteras: estudio de un caso de acción y reflexión intercultural y pedagógica. Teoría de la Educación. Revista Interuniversitaria, 24(1), 105-131

Iglesias Rodríguez, A. (2014). Discurso de Graduación. Grado de Maestro. Promoción 2010-2014. Ávila: Escuela Universitaria de Educación y Turismo (Universidad de Salamanca). Inédito

Iglesias Rodríguez, A. (2018). Proyecto Docente e Investigador. Salamanca: Universidad de Salamanca. Inédito 
Jiménez Cortés, R. (2010). Crear un documental: Diseño de una experiencia didáctica (ECTS) para formar al profesorado en educación inclusiva. Revista de Educación, 353, 723-739.

Jiménez Cortés, R. (2012). Educación inclusiva y formación inicial del profesorado: evaluación de una innovación didáctica basada en la producción cinematográfica desde la perspectiva del alumnado. Revista de Educación, (359), 232-259.

Madrid, M.J., Jiménez, N., León-Mantero, C. y Maz-Machado, A. (2017). Revistas brasileñas de educación en Scopus: un análisis bibliométrico. Biblios, 67. Recuperado de http://eprints.rclis.org/32816/1/RevistasBrasilenasDeEducacionEnSCOPUS.pdf

Maestre, M. del M., Nail, Ó. y Rodríguez-Hidalgo, A.J. (2017). Desarrollo de competencias TIC y para la educación inclusiva en la formación inicial práctica del profesorado. Bordón. Revista de Pedagogía, 69(3), 57-72. DOI: 10.13042/Bordon.2017. 51110

Martín, M.I. y Jiménez, A. (2013). Las tertulias literarias dialógicas, un desafío para la creatividad y la convivencia. Creatividad y Sociedad, 21, 1-21.

Martínez, R., De Haro, R. y Escarbajal, A. (2010). Una aproximación a la educación inclusiva en España. Revista Educación Inclusiva, 3(1), 149-164.

Mayor Zaragoza, F. (abril, 2019). 25 años después de la Declaración de Salamanca. Mesa Redonda llevada a cabo en el XVI Congreso Internacional y XXXVI Jornadas de Universidad y Educación Inclusiva "Nuevos retos en la formación del profesorado para la inclusión". Salamanca, España.

Messiou, K., Ainscow, M., Echeita, G., Goldrick, S., Hope, M., Paes, I., Sandoval, M., Simón, C. y Vitorino, T. (2014). Escuchar las voces de los estudiantes y planificar juntos. Cuadernos de Pedagogía, 446, 46-49.

Mirón Canelo, J.A., Iglesias de Sena, H., Alonso Sardón, M., Sánchez Fuentes, S., Fernández Lázaro, C.I., Chamorro Fernández, A.J., Santacruz Ruiz, S., Hernández Galilea, E., Santos García, J.Á., Fernández Martín, C. y Lorenzo-Gómez, M.F. (2019). Educación inclusiva en Medicina: una experiencia formativa sobre personas con discapacidad. Educación Médica, 20(S1), 16-24. Dol: https://doi.org/10.1016/j. edumed.2017.07.013

Moriña, A. y Carballo, R. (2018). Profesorado universitario y educación inclusiva: respondiendo a sus necesidades de formación. Psicología Escolar e Educacional, 22(edición especial), 87-95. Dol: http://dx.doi. org/10.1590/2175-3539/2018/053

Muñoz, M.L., López, M. y Assaél, J. (2015). Concepciones docentes para responder a la diversidad: ¿barreras o recursos para la in- 
clusión educativa? Psicoperspectivas, 14(3), 68-79. Dol: $10.5027 /$ psicoperspectivas-Vol14-Issue3-fulltext-646

Navarro-Montaño, M.J. (2017). Mejorar la calidad de la educación inclusiva: Propuesta de indicadores. Revista de Pedagogía, 38(102), 122-143.

Nisbet, J. y Suckmith, J. (1986). Estrategias de aprendizaje. Madrid: Santillana.

Núñez Mayán, M.T. (2019). El estancamiento de la inclusión educativa del alumnado con discapacidad. Revisión de su escolarización entre 1985 y 2015. Revista Nacional e Internacional de Educación Inclusiva, 12(1), 67-96.

Ocampo González, A. (2018). Competencia lectora y comprensión lectora desde una perspectiva de Educación inclusiva. Entrevista a Andrés Calero. Revista Electrónica de Investigación Educativa, 20(3), 1-12.

Organización de Naciones Unidas (ONU) (1994). Normas uniformes sobre la igualdad de oportunidades para las personas con discapacidad (A/ RES/48/96). Recuperado de https://www.un.org/spanish/disabilities/ standardrules.pdf

Organización de Naciones Unidas (ONu) (2015). Declaración Universal de los Derechos Humanos. Recuperado de https://www.un.org/es/ documents/udhr/UDHR_booklet_SP_web.pdf

Robinson, K. (2015). Escuelas creativas: la revolución que está transformando la educación. Barcelona: Grijalbo.

Rodríguez-García, A-M., Hinojo, M.A. y Ágreda, M. (2017). Análisis del uso de vídeo-tutoriales como herramienta de inclusión educativa. Publicaciones de la Facultad de Educación y Humanidades del Campus de Melilla, 47, 13-35.

Rouse, M. (2010). Reforming initial teacher education: A necessary but not sufficient condition for developing inclusive practice. In C. Forlin (ed.), Teacher education for inclusion: Changing paradigms and innovative approaches (pp. 47-56). Londres: Routledge.

Salinas, P. (1982). Poesías completas. Barcelona: Seix Barral.

Sharma, U. (2011). Teaching in inclusive classrooms: Changing heart, head, and hands. Bangladesh Education Journal, 10(2), 1-12. Recuperado de https://www.bafed.net/articles/EDec11a1.pdf

Shulman, L.S. (2005). Signature pedagogies in the professions. Daedalus, 134(3), 52-59. Recuperado de https://cdn.ymaws.com/www.cpedinitiative.org/resource/resmgr/Signature_Pedagogies_of_the_.pdf

Singleton, J. (2015). Head, heart and hands Model for transformative learning: Place as context for changing sustainability values. Journal of Sustainability Education, 9. Recuperado de http://www.jsedimensions.org/wordpress/wp-content/uploads/2015/03/PDF-SingletonJSE-March-2015-Love-Issue.pdf 
Tenti Fanfani, E. (2008). Dimensiones de la exclusión educativa y políticas de inclusión. Revista Colombiana de Educación, 54, 60-73.

Tiana Ferrer, A. (abril, 2019). 25 años después de la Declaración de Salamanca. Mesa Redonda llevada a cabo en el XVI Congreso Internacional y XXXVI Jornadas de Universidad y Educación Inclusiva "Nuevos retos en la formación del profesorado para la inclusión", Salamanca, España

Unesco (1990). Declaración mundial sobre educación para todos y marco de acción para satisfacer las necesidades básicas de aprendizaje. Nueva York. Recuperado de http://www.unesco.org/education/pdf/ JOMTIE_S.PDF

Unesco (1994). Declaración de Salamanca y marco de acción para las necesidades educativas especiales. Recuperado de http://www.unesco.org/education/pdf/SALAMA_S.PDF

Unesco (2015). Declaración de Incheón. Educación 2030. París. Recuperado de https://unesdoc.unesco.org/ark:/48223/pf0000245656_spa

Unicef (2006). Convención sobre los derechos del niño. Madrid. Recuperado de https://www.un.org/es/events/childrenday/pdf/derechos.pdf

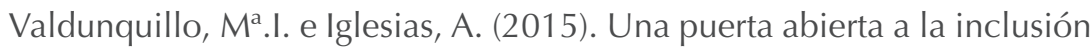
en la Universidad: Experiencia con un alumno Erasmus con Síndrome de Asperger. Revista Nacional e Internacional de Educación Inclusiva, 8(1), 104-114 


\section{Anexo I. Relación de artículos científicos analizados}

\begin{tabular}{|c|c|}
\hline Año & Artículos científicos seleccionados y analizados para el estudio \\
\hline 2019 & $\begin{array}{l}\text { Mirón, J.A., Iglesias de Sena, H., Alonso, M., Sánchez, S., Fernández, C.I., } \\
\text { Chamorro, A.J., Santacruz, S., Hernández, E., Santos, J.Á., Fernández, C. y } \\
\text { Lorenzo-Gómez, Ma.F. (2019). Educación inclusiva en Medicina: una experiencia } \\
\text { formativa sobre personas con discapacidad. Educación Médica, 20(S1), 16-24. }\end{array}$ \\
\hline 2018 & $\begin{array}{l}\text { Arnaiz, P., De Haro, R. y Azorín, C.M. (2018). Redes de apoyo y colaboración } \\
\text { para la mejora de la educación inclusiva. Profesorado, 22(2), 7-27. }\end{array}$ \\
\hline 2018 & $\begin{array}{l}\text { Boroel, B.I., Sánchez, J., Morales, K.D. y Henríquez, P.S. (2018). Educación } \\
\text { exitosa para todos: La tutoría como proceso de acompañamiento } \\
\text { escolar desde la mirada de la equidad educative. Revista Fuentes, } \\
\text { 20(2), 91-104. Dol: } 10.12795 / \text { revistafuentes.2018.v20.i2.06 }\end{array}$ \\
\hline 2018 & $\begin{array}{l}\text { Carrillo, S.M., Forgiony, J.O., Rivera, D.A., Bonilla, N.J., Montanchez, } \\
\text { Ma.L., \& Alarcón, M.F. (2018). Prácticas pedagógicas frente a la educación } \\
\text { inclusiva desde la perspectiva del docente. Espacios, 39(17), } 15 .\end{array}$ \\
\hline 2018 & $\begin{array}{l}\text { Llorens, J.B. y Díaz, A.M. (2018). Aspectos corporais e sociais a serem } \\
\text { considerados numa educação inclusiva; Aspectos corporales y sociales } \\
\text { a tener en cuenta en una educación inclusiva. Movimento, 24(4), } \\
\text { 1219-1234. Dol: https://doi.org/10.22456/1982-8918.82614 }\end{array}$ \\
\hline 2018 & $\begin{array}{l}\text { Moliner, O. y Ramel, S. (2018). Una mirada sobre el trabajo en red del } \\
\text { Laboratoire International sur l'inclusion scolaire (LISIS): Afianzando } \\
\text { una cultura colaborativa para la movilización del conocimiento } \\
\text { sobre educación inclusiva. Profesorado, 22(2), 69-87. }\end{array}$ \\
\hline
\end{tabular}

Moriña, A. y Carballo, R. (2018). Profesorado universitario y educación inclusiva:

2018 Respondiendo a sus necesidades de formación. Psicología Escolar e Educacional, 22(edición especial), 87-95. DOI: http://dx.doi.org/10.1590/2175-3539/2018/053

2018 Ocampo González, A. (2018). Competencia lectora y comprensión

2018 lectora desde una perspectiva de Educación inclusiva. Entrevista a Andrés Calero. Revista Electrónica de Investigación Educativa, 20(3), 1-12.

2017 Azorín Abellán, C.M. (2017). Una mirada desde los organismos internacionales a la educación para todos. Opción, 33(83), 203-228.

2017 Azorín Abellán, C.M. (2017). Análisis de instrumentos sobre educación inclusiva y atención a la diversidad. Revista Complutense de Educación, 28(4), 1043-1060.

2017 García-Barrera, A. (2017). Las necesidades educativas especiales: Un lastre conceptual para la inclusión educativa en España. Ensaio, 25(96), 721-742

Guerrero, H.R., Crissien, T.J. y Paniagua, R. (2017). Proyectos

2017 educativos institucionales colombianos (PEI): Educación inclusiva a través de la autoevaluación. Opción, 33(84), 218-266.

Maestre, M. del M., Nail, Ó. y Rodríguez-Hidalgo, A.J. (2017).

2017 Desarrollo de competencias TIC y para la educación inclusiva en la formación inicial práctica del profesorado. Bordón. Revista De Pedagogia, 69(3), 57-72. DOI: 10.13042/Bordon.2017.51110 


\begin{tabular}{|c|c|}
\hline Año & Artículos científicos seleccionados y analizados para el estudio \\
\hline 2017 & $\begin{array}{l}\text { Morales Romo, N. (2017). Las TIC y los escolares del medio rural, } \\
\text { entre la brecha digital y la educación inclusive. Bordón. Revista de } \\
\text { Pedagogía, 69(3), 41-56. Dol: } 10.13042 / \text { Bordon.2017.52401 }\end{array}$ \\
\hline 2017 & $\begin{array}{l}\text { Navarro-Montaño, M.J. (2017). Mejorar la calidad de la educación inclusiva: } \\
\text { Propuesta de indicadores. Revista de Pedagogía, 38(102), 122-143. }\end{array}$ \\
\hline 2017 & $\begin{array}{l}\text { Rodríguez-García, A-M., Hinojo, M.A. y Ágreda, M. (2017). Análisis del uso de } \\
\text { vídeo-tutoriales como herramienta de inclusión educativa. Publicaciones de la } \\
\text { Facultad de Educación y Humanidades del Campus de Melilla, 47, 13-35. }\end{array}$ \\
\hline 2017 & $\begin{array}{l}\text { Sampedro, B.E. y Maldonado, G.A. (2017). Valoraciones de los } \\
\text { estudiantes mexicanos y españoles sobre el uso de las tic como } \\
\text { recurso para trabajar la educación inclusiva. Bordón. Revista de } \\
\text { Pedagogía, 69(3), 89-106. Dol: 10.13042/Bordon.2017.51237 }\end{array}$ \\
\hline 2016 & $\begin{array}{l}\text { Gradaílle, R. y Caride, J.A. (2016). La Accesibilidad en las realidades } \\
\text { de la vida cotidiana: La pedagogía social en la construcción del } \\
\text { derecho a una educación inclusiva. Education Policy Analysis } \\
\text { Archives, 24. Dol: http://dx.doi.org/10.14507/epaa.24.2458 }\end{array}$ \\
\hline 2016 & $\begin{array}{l}\text { Herrera-Seda, C.M., Pérez-Salas, C.P. y Echeita, G. (2016). Teorías implícitas y } \\
\text { prácticas de enseñanza que promueven la inclusión educativa en la universidad. } \\
\text { Instrumentos y antecedentes para la reflexión y discusion. Formación } \\
\text { Universitaria, 9(5), 49-64. DOI: } 10.4067 / S 0718-50062016000500006\end{array}$ \\
\hline 2016 & $\begin{array}{l}\text { Rodríguez-Izquierdo, R.M } M^{a} \text {. (2016). Educación inclusiva: Perspectiva de los directores } \\
\text { de centros escolares en Andalucía, España. Revista de Ciencias Sociales, 22(3), 22-34. }\end{array}$ \\
\hline 2016 & $\begin{array}{l}\text { Sánchez Sánchez, L. (2016). Educación inclusiva con músicos invidentes: } \\
\text { Aprendizaje de la viola. Opción, 32(edición especial 10), 734-742. }\end{array}$ \\
\hline 2015 & $\begin{array}{l}\text { Albornoz, N., Silva, N. y López, M. (2015). Escuchando a los niños: Significados } \\
\text { sobre aprendizaje y participación como ejes centrales de los procesos de inclusión } \\
\text { educativa en un estudio en escuelas públicas en Chile. Estudios Pedagógicos, } \\
41 \text { (especial), 81-96. Dol: http://dx.doi.org/10.4067/S0718-07052015000300006 }\end{array}$ \\
\hline 2015 & $\begin{array}{l}\text { Colmenero, M.J., Pantoja, A. y Pegalajar, M.C. (2015). Percepciones } \\
\text { sobre atención a la diversidad en la formación inicial del profesorado de } \\
\text { Educación Secundaria. Revista Complutense de Educación, 26(1), 101- } \\
\text { 120. Dol: https://dialnet.unirioja.es/servlet/articulo?codigo=5754612 }\end{array}$ \\
\hline 2015 & $\begin{array}{l}\text { González, Á.L. y Blanco, M. (2015). Formación del profesorado de educación inclusiva: } \\
\text { Reto docente de la educación especial. Opción, } 31 \text { (edición especial 3), 582-604. }\end{array}$ \\
\hline 2015 & $\begin{array}{l}\text { Muñoz, M.L., López, M. y Assaél, J. (2015). Concepciones docentes para responder } \\
\text { a la diversidad: ¿barreras o recursos para la inclusión educativa? Psicoperspectivas, } \\
\text { 14(3), 68-79. Dol: } 10.5027 / \text { psicoperspectivas-Vol14-Issue3-fulltext-646 }\end{array}$ \\
\hline 2014 & $\begin{array}{l}\text { Arias Beatón, G. (2014). Una educación para todos y de calidad, una } \\
\text { máxima ética y política. Psicologia Escolar e Educacional, 18(2), 359- } \\
\text { 368. Dol: http://dx.doi.org/10.1590/2175-3539/2014/0182870 }\end{array}$ \\
\hline 2013 & $\begin{array}{l}\text { Bernal-Castro, C.A. y Moreno-Angarita, M. (2013). Aplicación de } \\
\text { sistemas de clasificación en contextos educativos: Facilitando los } \\
\text { procesos de inclusión de personas en situación de discapacidad } \\
\text { intellectual. Revista Facultad de Medicina, 61(2), 123-135. }\end{array}$ \\
\hline
\end{tabular}




\begin{tabular}{|c|c|}
\hline Año & Artículos científicos seleccionados y analizados para el estudio \\
\hline 2013 & $\begin{array}{l}\text { Bleck, J. y Guindo, B.M. (2013). ¿Educación para todos, educación para } \\
\text { quiénes, educación para qué? Development in Practice, 23(8), 1007- } \\
\text { 1021. Dol: http://dx.doi.org/10.1080/09614524.2013.839983 }\end{array}$ \\
\hline 2013 & $\begin{array}{l}\text { Fernández Batanero, J.M. (2013). Competencias docentes y educación } \\
\text { inclusiva. Revista Electronica de Investigación Educativa, 15(2), 82-99. }\end{array}$ \\
\hline 2013 & $\begin{array}{l}\text { Fernández, J.M. y Hernández, A. (2013). El Liderazgo como criterio de calidad } \\
\text { en la educación inclusiva. Estudios Sobre Educación, (24), 83-102. }\end{array}$ \\
\hline 2013 & $\begin{array}{l}\text { Fernández, J.M., \& Hernández, A. (2013). Liderazgo directivo e inclusión } \\
\text { educativa: Estudio de casos. Perfiles Educativos, 35(142), 27-41. }\end{array}$ \\
\hline 2013 & $\begin{array}{l}\text { Madariaga, J.M., Huguet, A. y Lapresta, C. (2013). Actitud, } \\
\text { presión social y educación inclusiva en aulas con diversidad } \\
\text { lingüística y cultural. Educación XX1, 16(1), 305-328. }\end{array}$ \\
\hline 2013 & $\begin{array}{l}\text { Martín-Padilla, E., Sarmiento, P.J. y Coy, L.Y. (2013). Educación inclusiva y Diversidad } \\
\text { funcional en la Universidad. Revista Facultad de Medicina, 61(2), 195-204. }\end{array}$ \\
\hline 2012 & $\begin{array}{l}\text { Jiménez Cortés, R. (2012). Educación inclusiva y formación inicial del profesorado: } \\
\text { Evaluación de una innovación didáctica basada en la producción cinematográfica } \\
\text { desde la perspectiva del alumnado. Revista de Educación, (359), 232-259. }\end{array}$ \\
\hline 2012 & $\begin{array}{l}\text { Sandoval, M., Simón, C. y Echeita, G. (2012). Análisis y valoración crítica de las } \\
\text { funciones del profesorado de apoyo desde la educación inclusiva. Revista de } \\
\text { Educación, (extra 2012), 117-137. Dol: 10.4438/1988-592X-RE-2012-EXT-209 }\end{array}$ \\
\hline 2012 & $\begin{array}{l}\text { Suriá Martínez, R. (2012). Discapacidad e integración educativa: ¿qué opina } \\
\text { el profesorado sobre la inclusión de estudiantes con discapacidad en sus } \\
\text { clases? Revista Española de Orientación y Psicopedagogía, 23(3), 96-109. }\end{array}$ \\
\hline 2011 & $\begin{array}{l}\text { Moriña Díez, A. (2011). Aprendizaje cooperativo para una educación inclusiva: } \\
\text { desarrollo del programa PAC en un aula de educación primaria. Estudios Sobre } \\
\text { Educación, (21), 199-216. Recuperado de http://hdl.handle.net/11441/66191 }\end{array}$ \\
\hline 2010 & $\begin{array}{l}\text { Dueñas Buey, M.L. (2010). Educacion Inclusiva. Revista Española } \\
\text { de Orientación y Psicopedagogía, 21(2), 358-366. Dol: https:// } \\
\text { doi.org/10.5944/reop.vol.21.num.2.2010.11538 }\end{array}$ \\
\hline 2010 & $\begin{array}{l}\text { Fernández Batanero, J.M. (2010). Estrategias y prácticas educativas } \\
\text { eficaces para la inclusión educativa: Un estudio de caso en } \\
\text { Andalucía. Education Policy Analysis Archives, 18, 1-25. }\end{array}$ \\
\hline 2010 & $\begin{array}{l}\text { Jiménez Cortés, R. (2010). Crear un documental: Diseño de } \\
\text { una experiencia didáctica (ECTS) para formar al profesorado en } \\
\text { educación inclusiva. Revista de Educación, 353, 723-739. }\end{array}$ \\
\hline 2010 & $\begin{array}{l}\text { Núñez, J.P. y Jódar, R. (2010). La integración socio-afectiva de } \\
\text { los niños con síndrome de down en aulas de integración y de } \\
\text { educación especial. Revista de Educación, 353, 549-569. }\end{array}$ \\
\hline 2009 & $\begin{array}{l}\text { Arnáiz Sánchez, P. (2009). Análisis de las medidas de atención a la diversidad } \\
\text { en la Educación Secundaria Obligatoria. Revista de Educación, 349, 203-223. }\end{array}$ \\
\hline
\end{tabular}




\section{Año Artículos científicos seleccionados y analizados para el estudio}

Barrios, M.E. y Mata, J.G. (2009). Las dificultades para la educación

2009 integradora desde la perspectiva de futuros maestros de inglés. RELIEVE. Revista Electronica de Investigación y Evaluación Educativa, 15(1), 1-24.

Echeita, G., Simón, C., Verdugo, M.Á., Sandoval, M., López, M., Calvo,

2009 I. y González-Gil, F. (2009). Paradojas y dilemas en el proceso de inclusión educativa en España. Revista de Educación, 349, 153-178.

Tapia, Y., Montero, S., Diz, M.E., Sánchez, M. y Campoy, M.J. (2009). Abordaje de

2009 las disfunciones orofaciales en alumnos con discapacidad motora y necesidades educativas especiales, siguiendo un modelo de intervención transdisciplinario. A propósito de un caso. Fisioterapia, 31(4), 163-173. DOI: 10.1016/j.ft.2008.11.003

2009 Verdugo, M.Á. y Parrilla, Á. (2009). Presentación. Aportaciones actuales a la educación inclusiva. Revista de Educación, 349, 15-22.

2008 Guijo Blanco, V. (2008). Derechos de la infancia (0-6 años) y educación inclusiva. Revista de Educación, 347, 55-74.

Muñoz, J.M., Casar, L.S. y Abalde, E. (2007). El "contexto y las "metas y objetivos" como elementos clave en la calidad de la atención a la diversidad en centros no universitarios. RELIEVE. Revista Electrónica de Investigación y Evaluación Educativa, 13(2), 235-261. 